\title{
Cerebellar Loops with Motor Cortex and Prefrontal Cortex of a Nonhuman Primate
}

\author{
Roberta M. Kelly ${ }^{1}$ and Peter L. Strick ${ }^{2}$ \\ ${ }^{1}$ Salk Institute for Biological Studies, La Jolla, California 92037, and ${ }^{2}$ Pittsburgh Veterans Affairs Medical Center and Center for the Neural Basis of \\ Cognition, Departments of Neurobiology, Neurosurgery, and Psychiatry, University of Pittsburgh School of Medicine, Pittsburgh, Pennsylvania 15261
}

We used transneuronal transport of neurotropic viruses to examine the topographic organization of circuits linking the cerebellar cortex with the arm area of the primary motor cortex (M1) and with area 46 in dorsolateral prefrontal cortex of monkeys. Retrograde transneuronal transport of the CVS-11 (challenge virus strain 11) strain of rabies virus in cerebello-thalamocortical pathways revealed that the arm area of M1 receives input from Purkinje cells located primarily in lobules IV-VI of the cerebellar cortex. In contrast, transneuronal transport of rabies from area 46 revealed that it receives input from Purkinje cells located primarily in Crus II of the ansiform lobule. Thus, both M1 and area 46 are the targets of output from the cerebellar cortex. However, the output to each area of the cerebral cortex originates from Purkinje cells in different regions of the cerebellar cortex. Anterograde transneuronal transport of the H129 strain of herpes simplex virus type 1 (HSV1) revealed that neurons in the arm area of M1 project via the pons to granule cells primarily in lobules IV-VI, whereas neurons in area 46 project to granule cells primarily in Crus II. Together, the findings from rabies and HSV1 experiments indicate that the regions of the cerebellar cortex that receive input from M1 are the same as those that project to M1. Similarly, the regions of the cerebellar cortex that receive input from area 46 are the same as those that project to area 46 . Thus, our observations suggest that multiple closed-loop circuits represent a fundamental architectural feature of cerebrocerebellar interactions.

Key words: rabies virus; transneuronal tracing; cerebral cortex; cerebellum; Purkinje cells; motor cortex; prefrontal cortex

\section{Introduction}

Cerebellar interconnections with the cerebral cortex were traditionally viewed as a massive open-loop system. At the input stage of this system, information from diverse cortical areas including motor, premotor, posterior parietal, cingulate, and prefrontal cortex is transmitted to the cerebellar cortex via corticopontocerebellar pathways (Brodal, 1978; Glickstein et al., 1985; Schmahmann and Pandya, 1997). At the output stage of processing, the cerebello-thalamocortical system was thought to project exclusively to the primary motor cortex (M1) (Evarts and Thach, 1969; Kemp and Powell, 1971; Allen and Tsukahara, 1974). Thus, the open-loop circuits formed by the interaction between the input and output stages of processing were believed to provide a route by which information from sensory, motor, and cognitive domains influenced the generation and control of movement at the level of M1.

The results of recent anatomical studies have raised questions about this view. For instance, there is now compelling evidence

\footnotetext{
Received March 27, 2003; revised July 21, 2003; accepted July 22, 2003.

This work was supported by the Veterans Affairs Medical Research Service and by United States Public Health Service Grants NS24328 and MH56661 (P.L.S.). We thank M. Page for the development of computer programs and W. Burnette, K. Hughes, and M. O'Malley-Davis for their expert technical assistance. We also thank Dr. C. Rupprecht (Centers for Disease Control, Atlanta, GA) for supplying the CVS-11 (challenge virus strain 11) strain of rabies, Dr. A. Wandeler (Animal Diseases Research Institute, Nepean, Ontario, Canada) for supplying antibodies to rabies, and Dr. R. D. Dix (Jones Eye Institute, Little Rock, AR) for supplying the H129 strain of HSV1.

Correspondence should be addressed to Dr. Peter L. Strick, Department of Neurobiology, University of Pittsburgh School of Medicine, W1640 Biomedical Science Tower, 200 Lothrop Street, Pittsburgh, PA 15261. E-mail: strickp@pitt.edu.

Copyright $\odot 2003$ Society for Neuroscience $\quad 0270-6474 / 03 / 238432-13 \$ 15.00 / 0$
}

that cerebellar efferents terminate in thalamic regions that innervate cortical areas other than M1 (Percheron et al., 1996). Therefore, the influence of the cerebellum on the cerebral cortex is more widespread than previously thought. In a series of studies using herpes simplex virus type 1 (HSV1) as a transneuronal tracer, we have shown that output from the dentate nucleus targets premotor, oculomotor, prefrontal, and posterior parietal areas of the cortex in addition to M1 (Lynch et al., 1994; Middleton and Strick, 1994, 2001; Hoover and Strick, 1999; Clower et al., 2001). The dentate regions that project to different cortical areas display little evidence of overlap. This suggests that each cortical area receives input from a distinct dentate "output channel" (Strick et al., 1993; Middleton and Strick, 1998; Dum and Strick, 2003).

We recently developed the use of rabies virus as a transneuronal tracer in the CNS of primates (Kelly and Strick, 2000). Rabies is transynaptically transported in the retrograde direction from cortical injection sites. With careful adjustment of the postinjection survival time, it is possible to use transneuronal transport of rabies to reveal the connections of three or more synaptically linked neurons.

In the experiments reported here, we used retrograde transneuronal transport of rabies to examine the distribution of Purkinje cells ("third-order" neurons) that project to the following two functionally distinct areas of the cerebral cortex: the arm area in M1 and area 46 in the dorsolateral prefrontal cortex. In doing so, we examined whether these cerebral cortical areas receive input from widespread or localized regions of the cerebellar cor- 
Table 1. Experimental protocols

\begin{tabular}{|c|c|c|c|c|c|c|c|}
\hline Animal & Area injected & Virus & $\begin{array}{l}\text { Surface } \\
\text { pens }\end{array}$ & $\begin{array}{l}\text { Sulcus } \\
\text { pens }\end{array}$ & $\begin{array}{l}\text { Total } \\
\text { injections }\end{array}$ & $\begin{array}{l}\text { Total volume } \\
(\mu \mathrm{l})\end{array}$ & $\begin{array}{l}\text { Survival } \\
\text { (d) }\end{array}$ \\
\hline K9 & M1 & CVS-11 & 10 & 5 & 25 & 5.0 & 2 \\
\hline K24 & M1 & CVS-11 & 8 & 0 & 39 & 7.8 & 2 \\
\hline K5 & M1 & CVS-11 & 10 & 5 & 25 & 5.0 & 3 \\
\hline K23 & M1 & CVS-11 & 10 & 0 & 50 & 10.0 & 3 \\
\hline K4 & M1 & CVS-11 & 10 & 5 & 25 & 5.0 & 4 \\
\hline K8 & M1 & CVS-11 & 7 & 5 & 22 & 4.4 & 4 \\
\hline K25 & M1 & CVS-11 & 9 & 0 & 45 & 9.0 & 4 \\
\hline K3 & M1 & CVS-11 & 10 & 5 & 25 & 5.0 & 5 \\
\hline K17 & M1 & H129 & 15 & 5 & 30 & 3.0 & 4 \\
\hline Z9 & M1 & H129 & 4 & 0 & 4 & 0.2 & 4 \\
\hline K10 & Area 46 & CVS-11 & 0 & 12 & 48 & 9.6 & 4 \\
\hline K11 & Area 46 & CVS-11 & 0 & 11 & 57 & 11.4 & 4 \\
\hline K18 & Area 46 & H129 & 0 & 9 & 43 & 8.6 & 4 \\
\hline K14 & Area 46 & H129 & 0 & 9 & 49 & 9.8 & 4 \\
\hline
\end{tabular}

tex. We then used anterograde transport of HSV1 to determine the distribution of granule cells in the cerebellar cortex that receive input from M1 and area 46. This enabled us to explore patterns of connectivity in cerebrocerebellar circuits and to determine whether these circuits are characterized by an open-loop or closed-loop architecture. Abstracts of these results have been reported previously (Kelly and Strick, 1997, 1998).

\section{Materials and Methods}

This report is based on observations from 14 Cebus apella monkeys (Cebus; 1.3-2 kg) (Table 1). In five of these animals, we placed multiple injections of rabies into $\mathrm{M} 1$ and allowed the animals to survive $2-5 \mathrm{~d}$ after injection to establish the time course of rabies transport. The analysis of data from these animals indicated that a $4 \mathrm{~d}$ survival period was optimal for examining virus transport from the cortical injection site to Purkinje cells (i.e., third-order connections; see below). Therefore, in another five animals, we placed multiple injections of rabies into the arm area of M1 $(n=3)$ or area $46(n=2)$ and allowed animals to survive for $4 \mathrm{~d}$ to determine the location of Purkinje cells in the cerebellar cortex that project to each injection site. In the remaining four animals, we placed multiple injections of the H129 strain of HSV1 into the arm area of M1 $(n=2)$ or area $46(n=2)$ and used anterograde transneuronal transport of this virus to determine the location of granule cells in the cerebellar cortex that receive input from each injection site. All experimental procedures were approved by the appropriate institutional animal care and biosafety committees and were in accordance with the regulations detailed in the National Institutes of Health Guide for the Care and Use of Laboratory Animals. Biosafety practices conformed to those outlined in Biosafety in Microbiological and Biomedical Laboratories (Department of Health and Human Services). Details of the procedures for handling virus and virus-infected animals were published previously (Strick and Card, 1992; Kelly and Strick, 2000).

Surgical procedures. Approximately $15 \mathrm{hr}$ before surgery, an animal was administered dexamethasone (Decadron; $0.5 \mathrm{mg} / \mathrm{kg}$, i.m.), and food and water were restricted. Animals were anesthetized with ketamine hydrochloride (Ketlar; $20 \mathrm{mg} / \mathrm{kg}$, i.m.) and then intubated and maintained on gas anesthesia (Enflurane; $1.5-2.5 \% ; 1-31 / \mathrm{m}$ ). Dexamethasone (Decadron; $0.5 \mathrm{mg} / \mathrm{kg}$, i.m.), glycopyrrolate (Robinul; $0.01 \mathrm{mg} / \mathrm{kg}$, i.m.), and an antibiotic (Rocephin; $75 \mathrm{mg} / \mathrm{kg}$, i.m.) were administered at the time of initial anesthesia. The animal's respiratory rate, blood oxygen level, body temperature, and sensitivity to pain were monitored at regular intervals for the duration of the surgical procedure. Hydration was maintained with lactated Ringer's solution $(10 \mathrm{cc} / \mathrm{hr}$, i.v.). Surgery was performed using aseptic techniques. The animal's head was secured in a Kopf stereotaxic frame (Kopf Instruments, Tujunga, CA), and the skin and muscle were retracted to expose the skull over the left hemisphere. A large craniotomy was made over the left frontal lobe, and the dura mater was cut and reflected medially to expose the cortical area of interest.
Virus injections. We used either the challenge virus strain 11 (CVS-11) strain of rabies $\left[\sim 1 \times 10^{7}\right.$ plaque forming units $(\mathrm{pfu}) / \mathrm{ml}$; supplied by Dr. Charles Rupprecht, Centers for Disease Control, Atlanta, GA] or the H129 strain of HSV1 ( $>1 \times 10^{8} \mathrm{pfu} / \mathrm{ml}$; supplied by Dr. Richard D. Dix, Jones Eye Institute, Little Rock, AR). The location of each injection site was based on surface landmarks and their known relationship to the cytoarchitectonic borders of M1 and prefrontal cortex (Walker, 1940; Woolsey et al., 1952; Barbas and Pandya, 1989; Dum and Strick, 1991). M1 injection sites included the anterior bank of the central sulcus and the surface of the precentral gyrus. Area 46 injection sites included the dorsal and ventral banks of the principal sulcus and were also guided by magnetic resonance images of the frontal lobe taken at least 1 week before surgery. The virus was delivered via a $5 \mu \mathrm{l}$ Hamilton (Reno, NV) syringe with a 28 gauge needle $(0.2-1 \mu \mathrm{l}$ of virus at each penetration site). Needle penetrations were spaced $1-1.5 \mathrm{~mm}$ apart, except to avoid blood vessels. The injection needle was left in place for 1-2 min after each deposit of the virus. When injections were complete, the dura mater and bone flap were repositioned, and the scalp incision was closed. An analgesic (Buprenex; $0.01 \mathrm{mg} / \mathrm{kg}$, i.m.) was administered every $12 \mathrm{hr}$ for the first $24 \mathrm{hr}$ after surgery. Decreasing doses of dexamethasone (Decadron; 0.5-0.25 mg/ $\mathrm{kg}$, i.m. or oral) were administered for $2 \mathrm{~d}$ after surgery.

Histological procedures. At the end of the survival period, animals were deeply anesthetized with ketamine hydrochloride (Ketlar; $25 \mathrm{mg} / \mathrm{kg}$, i.m.) followed by pentobarbital sodium (Nembutal; $37 \mathrm{mg} / \mathrm{kg}$, i.p.) and were transcardially perfused with a three-step procedure adapted from Rosene and Mesulam (1978). The perfusates included 0.1 м PBS, 10\% buffered formalin ( $\sim 4.0 \%$ formaldehyde), and $10 \%$ buffered formalin with $10 \%$ glycerol added. After the perfusion, the brain and spinal cord were removed and stored in $10 \%$ formalin with $20 \%$ glycerol $\left(4^{\circ} \mathrm{C}\right)$ for 3-10 d.

Frozen blocks of tissue were serially sectioned $(50 \mu \mathrm{m})$ in the coronal or sagittal plane. Every tenth section was stained with cresyl violet for the analysis of cytoarchitecture. To identify virus-infected neurons, freefloating tissue sections were processed according to the avidin-biotin peroxidase method (Vectastain; Vector Laboratories, Burlingame, CA). Rabies antigen was detected using a monoclonal antibody directed against the nucleoprotein of rabies virus (5DF12; diluted 1:100; supplied by Dr. Alex Wandeler, Animal Diseases Research Institute, Ontario, Canada). HSV1 antigen was detected using a commercially available polyclonal antibody (diluted 1:2000; Dako, Carpinteria, CA). Every other tissue section was processed using this technique. Reacted tissue sections were mounted on gelatin-coated glass slides, air dried, and coverslipped with either Artmount or DPX (a mixture of distyrene, tricresyl phosphate, and xylene).

Analytical procedures. We examined at least every fourth section through the injection site, thalamus, and cerebellum of experimental animals. Sections reacted for rabies or HSV1 were examined using bright-field, dark-field, and polarized illumination. Data from all exper- 
iments were plotted using a personal computer-based charting system (MD2; MN Datametrics, St. Paul, MN). This system used optical encoders to sense $\mathrm{X}-\mathrm{Y}$ movements of the microscope stage and stored the coordinates of charted structures (e.g., section outlines, injection site zones, and labeled neurons). To chart sections from experiments with rabies, we plotted the location of each labeled cell. To chart sections from experiments with HSV1, we plotted the location and relative density of labeled cells, because too many cells were labeled to plot them individually. Digital images of selected structures were "captured" from the microscope using a video camera coupled to a high-resolution videoprocessing board in a personal computer. Software written in the laboratory enabled us to generate high-resolution composites from multiple images.

Determination of injection sites. At the time of virus injections, we made a detailed drawing or took photographs of the cortical area to be injected. These pictures included important landmarks such as cortical sulci and major blood vessels. As each injection was made, its location was marked on an enlarged version of each picture. This information was used to aid in the reconstruction of injection needle tracks from single sections of tissue.

When the H129 strain of HSV1 was used as a tracer, we could define "central" and "peripheral" concentric zones of immunoreactive labeling at the cortical injection sites. The central zone, located immediately adjacent to the needle track, was characterized by dense and primarily uniform immunoreactive staining for virus and marked tissue necrosis. In some instances, this zone was lost during histological processing. The peripheral zone contained a less dense accumulation of reaction product, as well as some neuronal lysis. In this zone, some darkly labeled neurons in an advanced phase of infection could be distinguished from the background staining of the neuropil. In each experiment, we used the central zone of labeling to define the H129 injection site (see Fig. 1).

In general, staining for rabies virus at injection sites was less dense than H129 staining at comparable injection sites. Rabies injection sites did not contain zones with dense background staining, glial labeling, or pathology (Gillet et al., 1986). Therefore, to define rabies injection sites, we reconstructed each penetration of the injection needle and plotted the distribution of labeled neurons around them (see Figs. 3, 8).

Reconstruction of cerebellar cortical labeling. To display the overall distribution of labeled Purkinje and granule cells, we created flattened maps of the cerebellar surface that show the labeled neurons in relationship to the major lobules of the cerebellum according to Larsell (1970). This involved measuring the linear distance of individual lobules on plots of sagittal sections. Those distances were then charted using the middle of lobule I as an alignment point. Lateral regions of the cerebellum (in which lobule I was no longer present) were added to these maps by extending the natural direction of a lobule using photographs of the cerebellar surface as a guide. Labeled Purkinje and granule cells located on the exposed surface of a lobule were placed at the appropriate location on these maps.

To illustrate the location of labeled neurons buried in cerebellar fissures, we also created unfolded maps of the fissures in regions containing large numbers of labeled neurons. We generated these maps by measuring the linear distance from the cerebellar surface to the fundus of relevant fissures on sagittal sections. The fundus of a fissure was used as the alignment point to chart the results from different sections. The outlines of the lobule surfaces were added from the flattened maps. Gaps between some lobule surfaces and adjacent fissures represent "cuts" made in the maps to enable the complex three-dimensional structure of the cerebellum to be represented in two dimensions. Labeled Purkinje or granule cells were then placed at the appropriate locations on these maps.

\section{Results}

Our findings are presented in two sections. In the first, we describe the spatial and temporal features of rabies transport in cerebrocerebellar circuits (Fig. 1). These circuits are particularly useful for defining features of rabies transport, because their general synaptic organization has been well characterized (Allen and Tsukahara, 1974; Ito, 1984) and they have proven useful for ex-

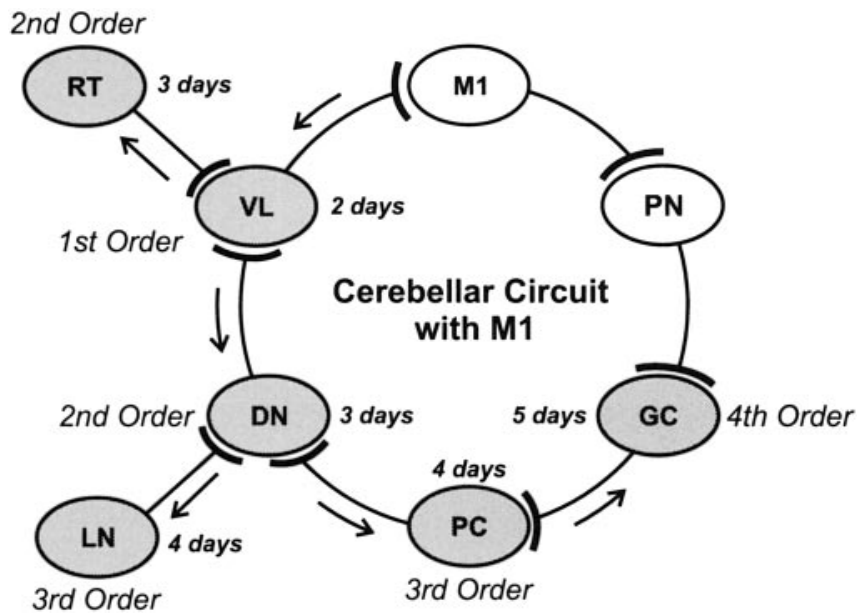

Figure 1. Retrograde transneuronal transport of rabies virus in the cerebrocerebellar circuit. See Results for a complete description. CN, Cerebellar nuclei; LCl, local circuit interneurons in the cerebellar nuclei; PC, Purkinje cells; GC, granule cells; PN, pontine nuclei; RT, reticular nucleus of the thalamus; $V L$, ventrolateral thalamus.

amining transneuronal transport of other viral tracers (Zemanick et al., 1991; Hoover and Strick, 1999). Analysis of the time course of rabies transport enabled us to select a survival time that was appropriate for examining connections between the cerebellar cortex and specific areas of the cerebral cortex. In the second section, we described the results of the experiments in which rabies and H129 were used as transneuronal tracers to reveal the macroarchitecture of the circuits that link the cerebellar cortex with $\mathrm{M} 1$ and area 46 . We also observed transneuronal transport of rabies in basal ganglia circuits with the cerebral cortex (Kelly and Strick, 2003). However, because of the complexity of these connections, the distribution of labeled neurons in that system will be presented in a separate communication.

\section{General features of rabies infection}

To examine the direction and rate of rabies transport, we injected the virus into the arm area of M1 and allowed the animals to survive for $2-5$ d (Table 1 ). The rabies virus was retrogradely transported from the cortical injection site in all animals. None of the animals displayed any symptoms of infection. Neurons infected with rabies contained small immunostained inclusions that were confined to their soma and dendrites (Fig. 2). Infected neurons displayed no evidence of lysis, and we saw no evidence of tissue destruction at any survival time. We also saw no immunostaining of glial cells either surrounding the injection site or in other regions that contained labeled neurons.

\section{Rabies injection sites}

Two days after cortical injections of rabies, dense accumulations of labeled neurons were present around each penetration of an injection needle. However, no dense or even diffuse staining of the neuropil was present around injection sites. The region that contained a uniform high density of labeled neurons spread $200-$ $500 \mu \mathrm{m}$ from each penetration, depending on the amount of virus injected (Fig. 3). Less dense accumulations of labeled neurons were also present in cortical areas that are known to innervate the injection site (Fig. 3, PMv and PMd in K24, $2 \mathrm{~d}$ survival).

At longer survival times, the density of labeled neurons at the injection site and in cortical areas that project to the injection site increased (Fig. 3, K25, 4 d survival). However, the overall spatial distribution of the peaks in the density of labeled neurons re- 


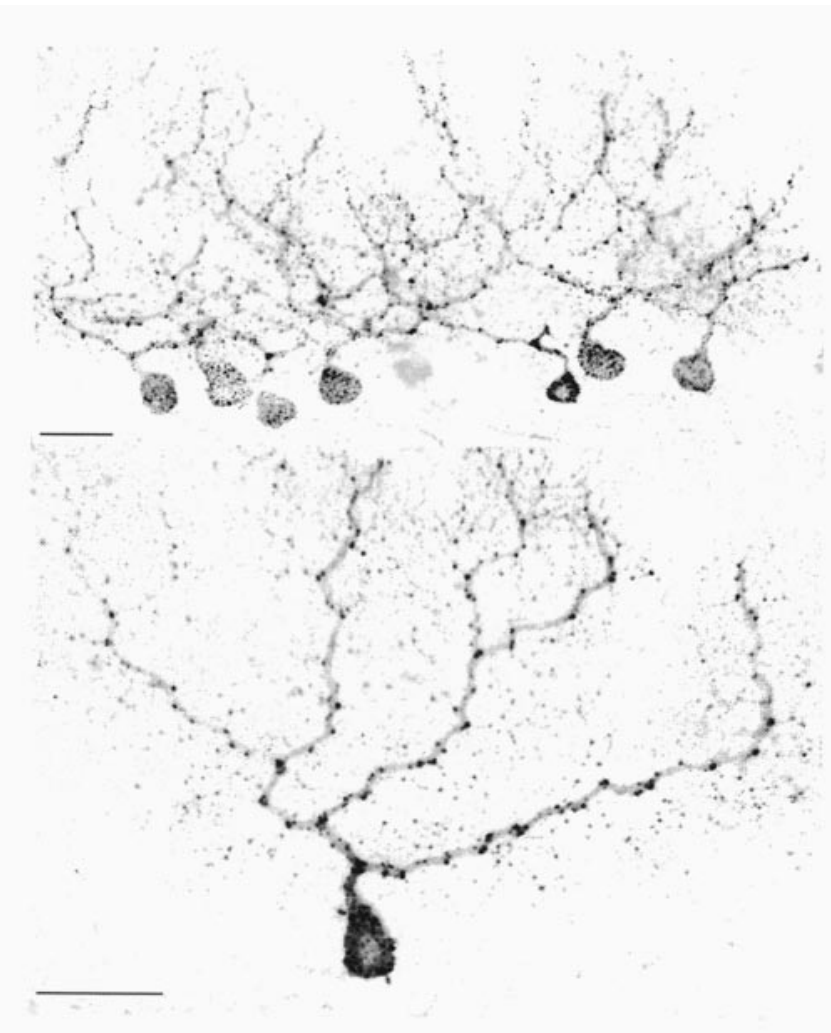

Figure 2. Purkinje cells infected with rabies. Top, A cluster of injected Purkinje cells found on a sagittal section through the cerebellar hemisphere. Bottom, An isolated infected Purkinje cell in which large portions of the dendritic tree are labeled. Scale bar, $50 \mu \mathrm{m}$.

mained comparable with what was observed in animals that survived for only $2 \mathrm{~d}$. On the basis of these observations, we considered the region within $500 \mu \mathrm{m}$ of each needle penetration (i.e., the distribution of labeled neurons that we observed at the $2 \mathrm{~d}$ survival time) to be a conservative estimate of the effective site of rabies uptake.

\section{Time course of transport}

Two days after $M 1$ injection

We saw labeled neurons at all regions known to project to M1, such as multiple cortical areas in the frontal and parietal lobes, the basal forebrain, and several thalamic nuclei (for review, see Dum and Strick, 1991). For example, "first-order" neurons, which innervate the injection site, were labeled in portions of the ventrolateral thalamus that are known to project to the arm area of $\mathrm{M} 1$, including nucleus ventralis posterior lateralis pars oralis (VPLo) and nucleus ventralis lateralis pars oralis (VLo) (Olsewski, 1952; Matelli et al., 1989; Holsapple et al., 1991). This pattern of labeling is consistent with retrograde transport of rabies from cortical injection sites.

In contrast, we did not see any labeled neurons at sites that receive projections from $\mathrm{M} 1$ but do not project back to it. For example, no labeling was present in the pontine nuclei, striatum, red nucleus, or reticular nucleus of the thalamus (Kunzle, 1975; Brodal, 1978; Kuypers, 1981; Glickstein et al., 1985; Jones, 1985). Thus, $2 \mathrm{~d}$ after injection, there was no evidence of anterograde transport of rabies from cortical injection sites.

Three days after M1 injection

With longer survival times, we observed a pattern of labeling that differed in two major respects from that described above. First,
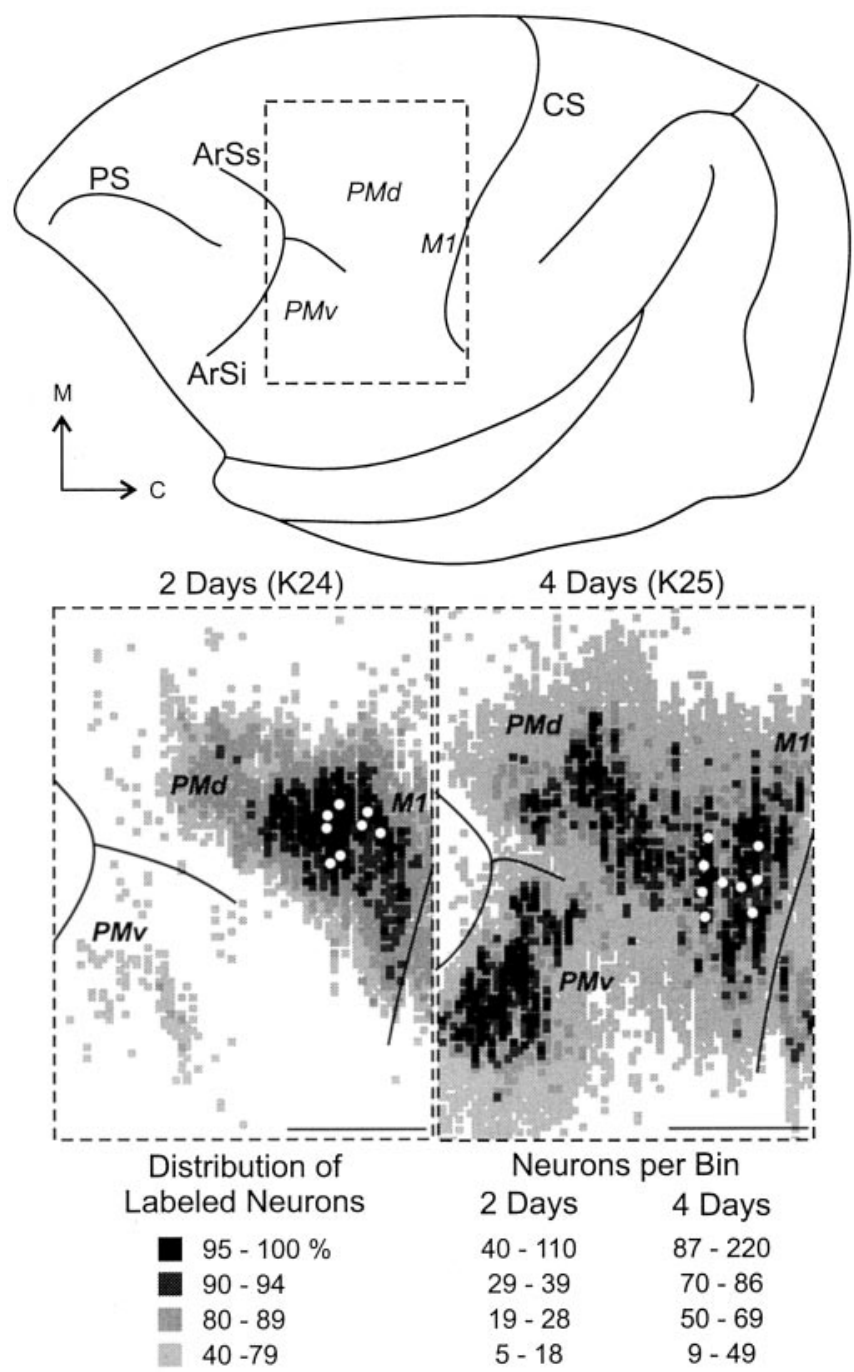

Figure 3. Density maps of labeled neurons after rabies injections in M1. Top, Lateral view of the left hemisphere of the Cebus monkey. The enclosed area is enlarged at the bottom. Bottom, Density and distribution of immunolabeled neurons $2 \mathrm{~d}$ (left) and $4 \mathrm{~d}$ (right) after rabies injections into M1. The darkest pixels indicate the greatest concentration of labeled neurons (see scale). White dots indicate where the virus injection needle penetrated the cerebral cortex. Scale bars, $5 \mathrm{~mm}$. ArSs, Superior limb of the arcuate sulcus; ArSi, inferior limb of the arcuate sulcus; CS, central sulcus; PS, principal sulcus.

there was an increased number of labeled neurons at all sites infected at the $2 \mathrm{~d}$ survival time. Second, infected neurons were present at sites that were not labeled previously, including the cerebellar nuclei (primarily dentate and interpositus), internal segment of the globus pallidus (GPi), and reticular nucleus of the thalamus. Neurons in each of these regions are known to project to thalamic nuclei that contained labeled neurons at the $2 \mathrm{~d}$ survival time. For instance, efferents from the dentate terminate densely in VPLo, and efferents from GPi terminate densely in VLo (for review, see Percheron et al., 1996).

The distribution of labeled neurons in the dentate and GPi was similar to that reported by Hoover and Strick (1993, 1999) after retrograde transneuronal transport of HSV1 from the arm area of M1. For instance, labeled dentate neurons were concentrated dorsally in the middle third of the nucleus (Figs. 4, 5) [see Fig. 16 in Hoover and Strick (1999)]. The pattern of labeling in the dentate, GPi, and reticular nucleus of the thalamus (Fig. 6) is consistent with uptake and retrograde transport of rabies by first- 


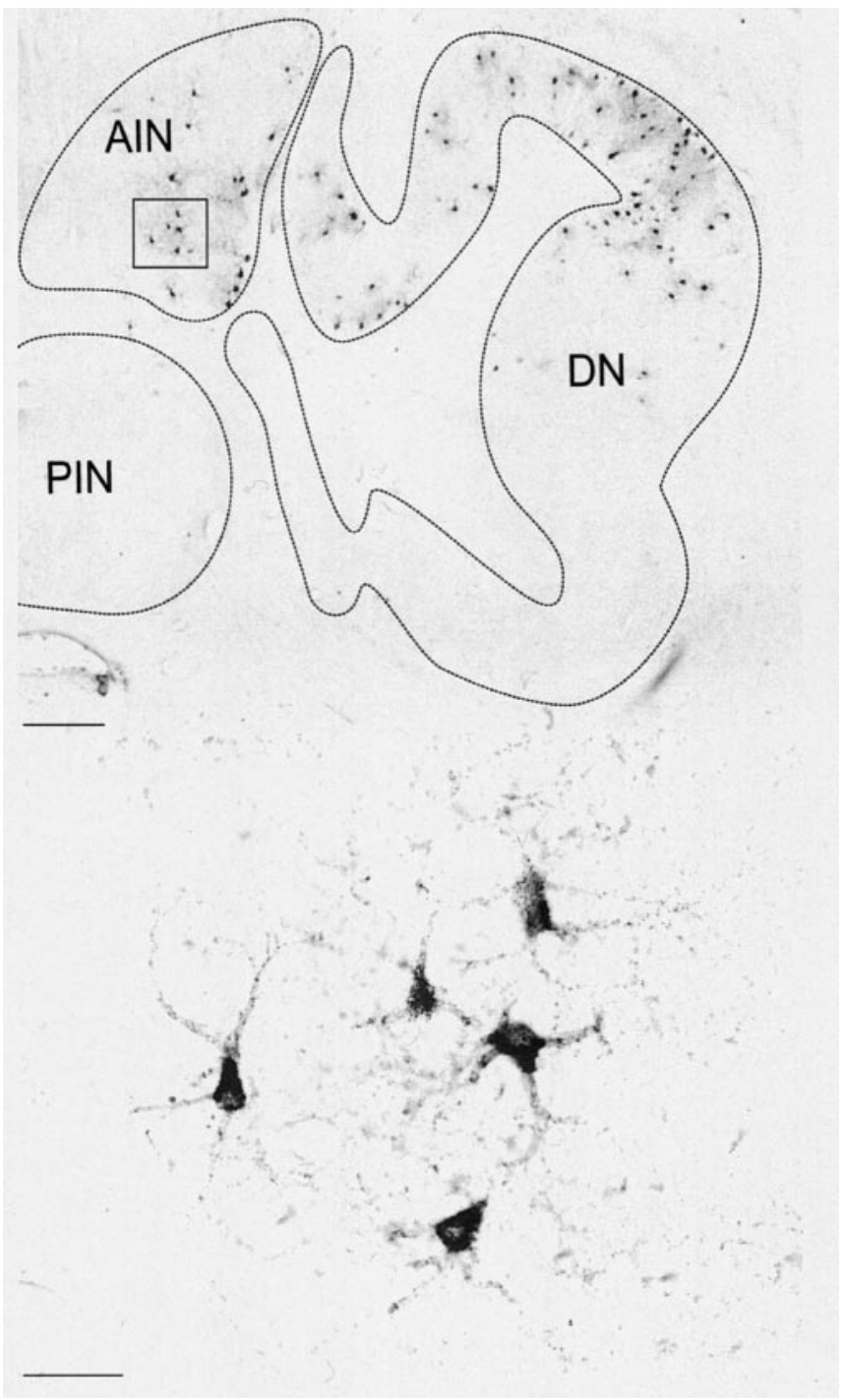

Figure 4. Neurons in the cerebellar nuclei infected with rabies. Top, Infected cells found on a transverse section through the cerebellar nuclei $3 \mathrm{~d}$ after rabies was injected in the arm area of M1. Scale bar, $200 \mu \mathrm{m}$. Bottom, Enlarged view of some labeled neurons in anterior interpositus (the area enclosed at the top). Scale bar, $50 \mu \mathrm{m}$. AIN, Anterior interpositus nucleus; PIN, posterior interpositus nucleus; $\mathrm{DN}$, dentate nucleus.

order neurons in the thalamus, which innervate the injection site, and then retrograde transneuronal transport of the virus from those first-order neurons to "second-order" neurons in the three subcortical nuclei.

Overall, we observed no evidence of anterograde transport of the virus from the injection site to the subcortical targets of M1. One could argue that the labeling in the reticular nucleus, which is a target of M1 efferents (Jones, 1985), is evidence of anterograde transport. The reason we believe this is not the case is that other targets of M1 efferents, including the pontine nuclei, striatum, and red nucleus, remained free of labeled neurons at the $3 \mathrm{~d}$ survival time. Thus, the most likely explanation for the labeling in the reticular nucleus is that it resulted from retrograde transneuronal transport of virus from first-order neurons in the thalamus (Fig. 1).

Four days after $M 1$ injection

There was an increased number of infected neurons at all sites labeled at the 2 and $3 \mathrm{~d}$ survival times. In addition, new sets of

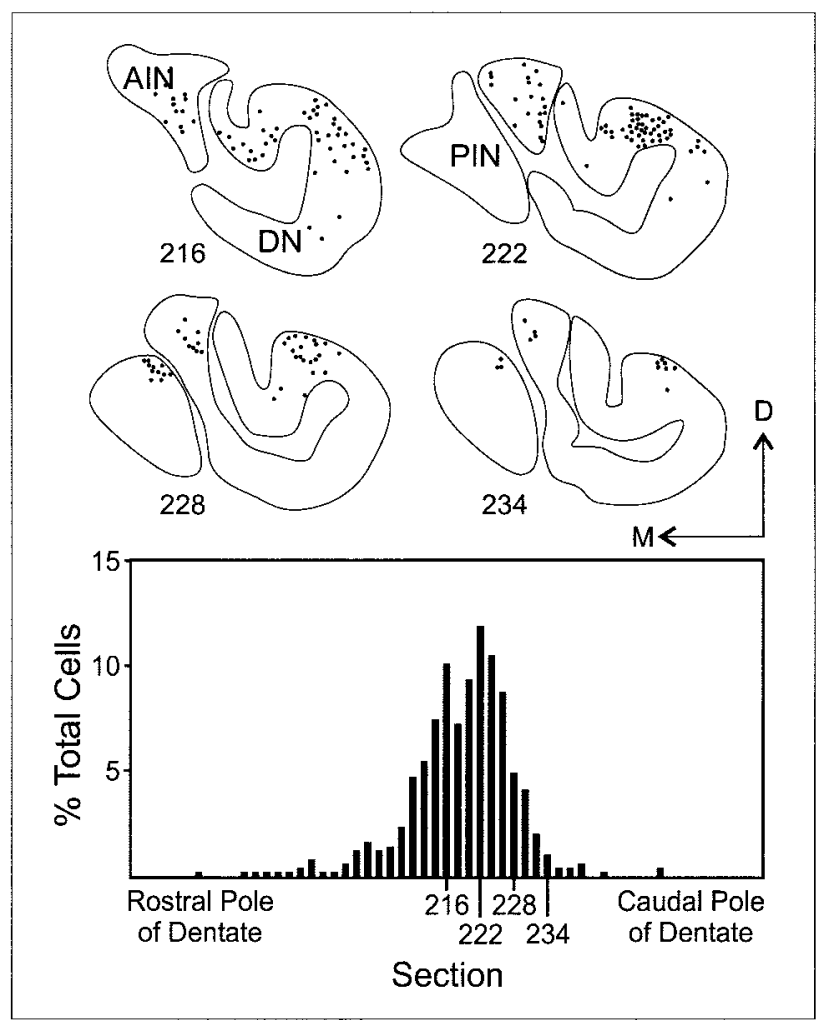

Figure 5. Distribution of infected neurons in the cerebellar nuclei. The plots are transverse sections through the cerebellar nuclei. The small black dots represent labeled neurons found $3 \mathrm{~d}$ after rabies was injected in the arm area of $\mathrm{M} 1$. Scale bar, $1 \mathrm{~mm}$. The graph shows the distribution of second-order neurons in the anterior-posterior extent of the dentate nucleus. Plotted sections are taken from the level indicated on the $x$-axis of the graph. AIN, Anterior interpositus nucleus; PIN, posterior interpositus nucleus; DN, dentate nucleus; FN, fastigial nucleus.

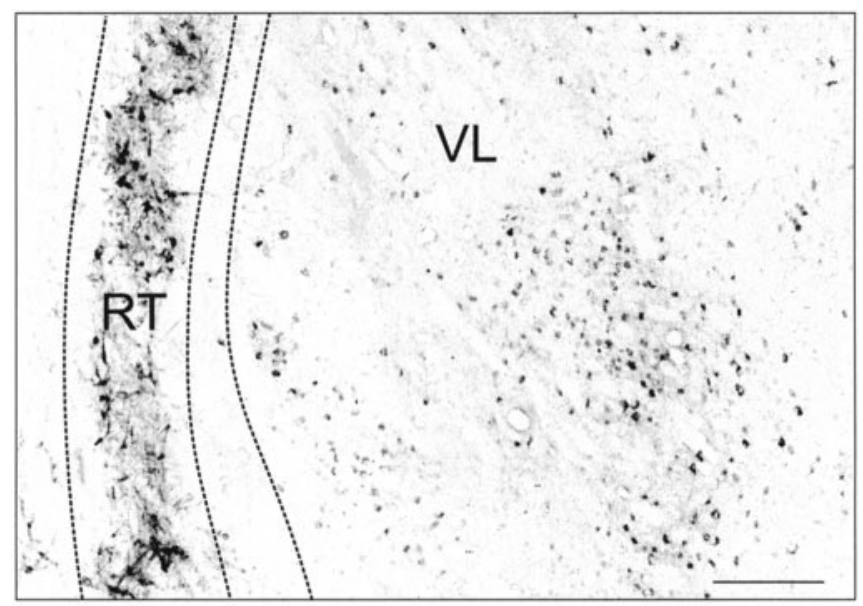

Figure 6. Immunolabeled neurons in the thalamus. This is a photograph of a transverse section through the thalamus $4 \mathrm{~d}$ after rabies was injected into the $\mathrm{M} 1 \mathrm{arm}$ area. At the $4 \mathrm{~d}$ survival time, first-, second-, and third-order neurons are labeled in subdivisions of the ventrolateral thalamus (VL), whereas labeling in the reticular nucleus of the thalamus (RT) is restricted to second- and third-order neurons. Scale bar, $200 \mu \mathrm{m}$.

infected neurons were present at sites not previously labeled, including Purkinje cells in the cerebellar cortex (Figs. 2, 7) and neurons in the external segment of the globus pallidus (GPe), putamen, and subthalamic nucleus (STN). Neurons at each of these sites are known to project to regions of the cerebellar nuclei and GPi that contain labeled neurons at the $3 \mathrm{~d}$ survival time 


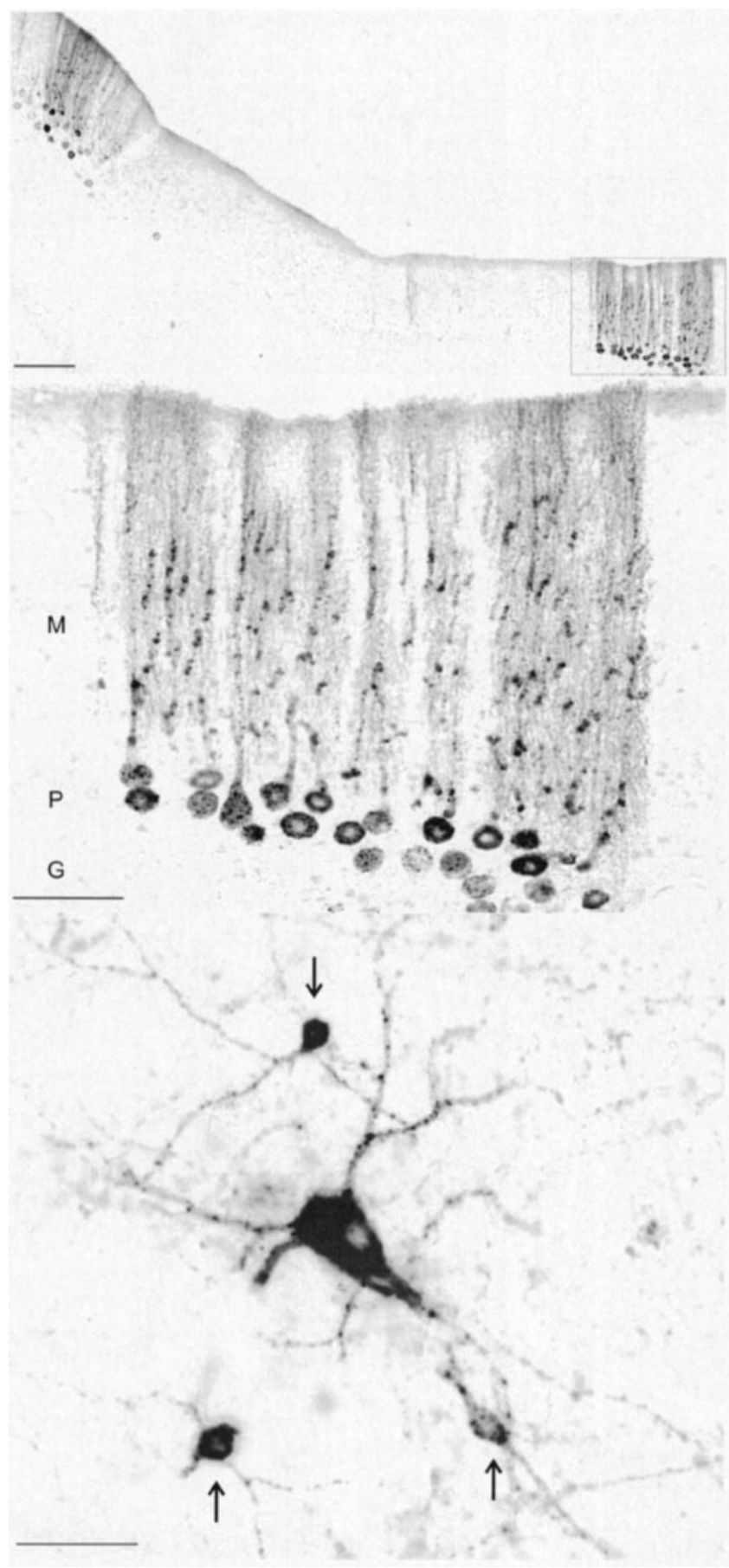

Figure 7. Cerebellar neurons labeled by retrograde transneuronal transport of rabies $4 \mathrm{~d}$ after an injection of the virus into the arm area of M1. Top, Infected Purkinje cells seen on a transverse section through the lateral cerebellum. Scale bar, $500 \mu \mathrm{m}$. Middle, Enlarged view of the infected cells enclosed by the box at the top. Scale bar, $50 \mu \mathrm{m}$. M, Molecular layer; $P$, Purkinje cell layer; $G$, granule cell layer. Bottom, Infected second-and third-order neurons in the anterior interpositus nucleus $4 \mathrm{~d}$ after an injection of rabies into $\mathrm{M} 1$. The $4 \mathrm{~d}$ survival time is long enough to allow labeling of third-order neurons. The small labeled neurons (arrows) are typical of third-order, local circuit interneurons that were first seen in the cerebellar nuclei $4 \mathrm{~d}$ after cortical injections of rabies. Scale bar, $50 \mu \mathrm{m}$.

(Eager, 1966; Haines and Rubertone, 1979; Tolbert and Bantli, 1979; Parent and Smith, 1987; Parent and Hazrati, 1995). Overall, the pattern of labeling at the $4 \mathrm{~d}$ survival time is consistent with uptake and retrograde transport of rabies by the following: (1) first-order thalamic neurons that innervate the injection site, (2)

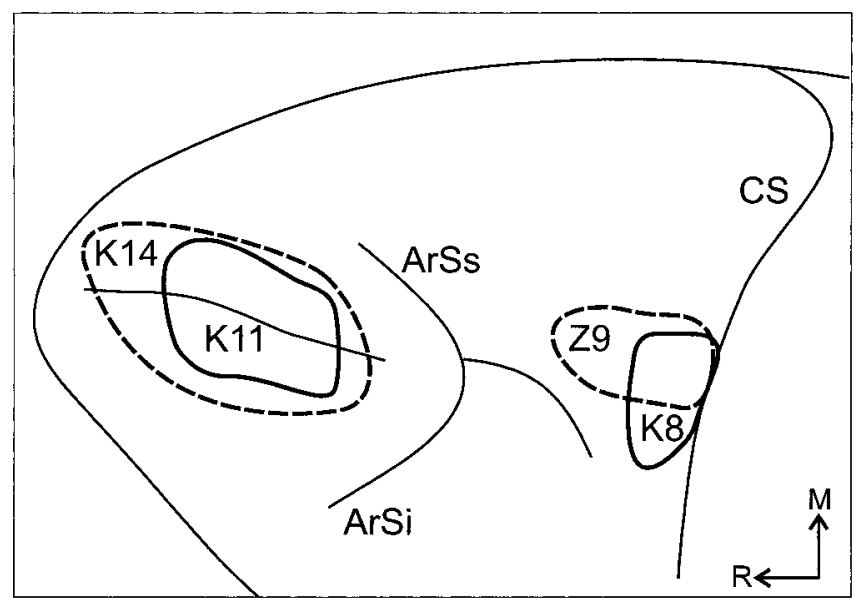

Figure 8. Effective regions of virus uptake after rabies (solid lines) and H129 (broken lines) injections into $\mathrm{M} 1$ and area 46 in four representative animals (see Table 1 for details). Scale bar, $3 \mathrm{~mm}$. ArSs, Superior limb of the arcuate sulcus; ArSi, inferior limb of the arcuate sulcus; CS, central sulcus.

retrograde transneuronal transport of virus from those firstorder neurons to second-order neurons in the output nuclei of the cerebellum and basal ganglia, and (3) an additional stage of retrograde transneuronal transport of virus from those secondorder neurons to third-order neurons in the cerebellar cortex, GPe, putamen, and STN (Fig. 1).

Additional support for this interpretation comes from changes in the pattern of labeling in the cerebellar nuclei at different survival periods. At the $3 \mathrm{~d}$ survival time, labeling in the cerebellar nuclei was confined to large neurons with round or elliptical-shaped cell bodies and multiple dendrites from the soma (Fig. 4). Those cells are typical of projection neurons in the cerebellar nuclei (Chan-Palay, 1977; Tolbert et al., 1978; Nakano et al., 1980). At the $4 \mathrm{~d}$ survival time, the labeling also included a set of small neurons with round cell bodies that were intermingled among the large labeled neurons (Fig. 7, bottom). The small neurons are typical of a type of interneuron in the cerebellar nuclei (Chan-Palay, 1977). Labeling of those neurons at the $4 \mathrm{~d}$ survival time is consistent with retrograde transneuronal transport of virus from second-order (projection) neurons labeled at the $3 \mathrm{~d}$ survival time (Fig. 1).

Five days after M1 injection

In one animal, we examined the cerebellum $5 \mathrm{~d}$ after rabies was injected in the arm area of M1. Many more labeled neurons were present in the cerebellar nuclei and cortex at $5 \mathrm{~d}$ than at $4 \mathrm{~d}$. Newly labeled neurons in the cerebellar cortex included granule cells. Granule cells are known to have axons that extend into the outer molecular layer of the cerebellar cortex and form parallel fibers that synapse on the dendritic spines of Purkinje cells (Ito, 1984). Thus, the labeling in the cerebellar cortex at $5 \mathrm{~d}$ survival time indicates that rabies underwent an additional stage of retrograde transneuronal transport from third-order (Purkinje) neurons to "fourth-order" granule cells.

In summary, our results indicate that rabies is transported selectively in the retrograde direction after intracortical injections in primates. On the basis of the patterns of labeling that we observed, transneuronal transport of rabies appears to take place exclusively at synaptic connections (Iwasaki and Clark, 1975; Charlton and Casey, 1979; Ugolini, 1995). Furthermore, transport occurred in a time-dependent manner. Thus, with careful adjustment of survival time, transneuronal transport of rabies 

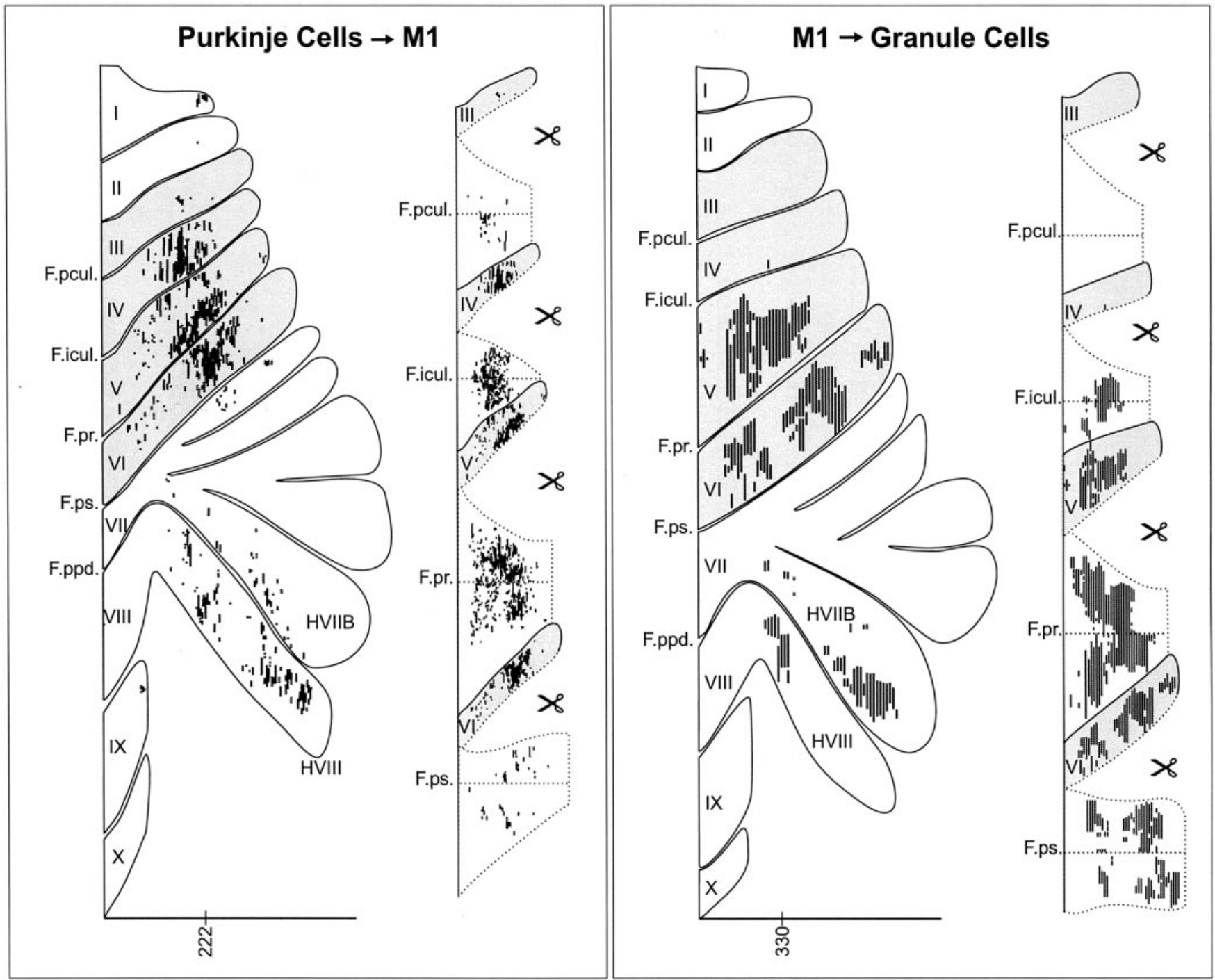

Figure 9. Input- output organization of the cerebellar loops with M1. Left, The distribution of Purkinje cells (small dots) that project to the arm area of M1. These neurons were labeled after retrograde transneuronal transport of rabies from injections into the arm area of $\mathrm{M} 1$. Right, The distribution of granule cells (fine lines) that receive input from the arm area of $\mathrm{M} 1$. These neurons were labeled after anterograde transneuronal transport of the $\mathrm{H} 129$ strain of HSV1 from injections into the arm area of M1. The shaded areas on the flattened surface maps (diagrams on the left in each panel) are unfolded on the right side of each panel to show the distribution of labeled neurons in the relevant cerebellar cortical fissures. The small icons of scissors in the diagram indicate places where the maps have been cut to facilitate the unfolding process (see Materials and Methods for details about unfolding). Scale bars, $15 \mathrm{~mm}$. Nomenclature and abbreviations are according to Larsell (1970). The numbers on the scale bars indicate the location of the sections displayed in Figure 10.

can be used to reveal different links in a chain of synaptically connected neurons.

Topographic arrangement of Purkinje cells that project to M1 and area 46

A major goal of the present study was to determine how output from the cerebellar cortex maps on the arm area of M1 and area 46. This required an adjustment of postinjection survival times to allow labeling of Purkinje cells (i.e., third-order neurons) but not granule cells (i.e., fourth-order neurons) in the cerebellar cortex (Fig. 1). Our analysis of the temporal features of rabies transport demonstrated that third-order labeling occurs $4 \mathrm{~d}$ after the virus is injected into the cerebral cortex. Therefore, we used a $4 \mathrm{~d}$ survival time to examine the distribution of labeled Purkinje cells after rabies injections into the arm area of M1 $(n=3)$ or area 46 $(n=2)$ (Fig. 8). For ease of comparison, we present the results from one representative animal in each group whose cerebellar cortex was sectioned in the sagittal plane.
M1

Four days after rabies injections in the arm area of M1, we found infected Purkinje cells in two separate regions of the cerebellar cortex contralateral to the injection site. The majority of the labeled cells ( $\sim 80 \%$ of the sample) was located anteriorly in lobules IV-VI, and the remainder was located posteriorly in lobules HVIIB-HVIII (Fig. 9, left; Fig. 10, top). In both regions, labeled Purkinje cells were found on the exposed cortical surface and buried within fissures.

Labeled neurons were not homogeneously distributed in these regions but formed clusters of varying density. Few labeled Purkinje cells were seen in the vermis at any anterior-posterior level. In lobules IV-VI, the clusters began $4 \mathrm{~mm}$ from the midline and continued for $3 \mathrm{~mm}$ laterally. They occupied the middle third of the lobules mediolaterally. The clusters in lobules IV-VI tended to be longitudinally aligned. In lobules HVIIB-HVIII, the clusters were more dispersed and contained fewer neurons. They began $5 \mathrm{~mm}$ from the midline and continued for $7 \mathrm{~mm}$ laterally. 

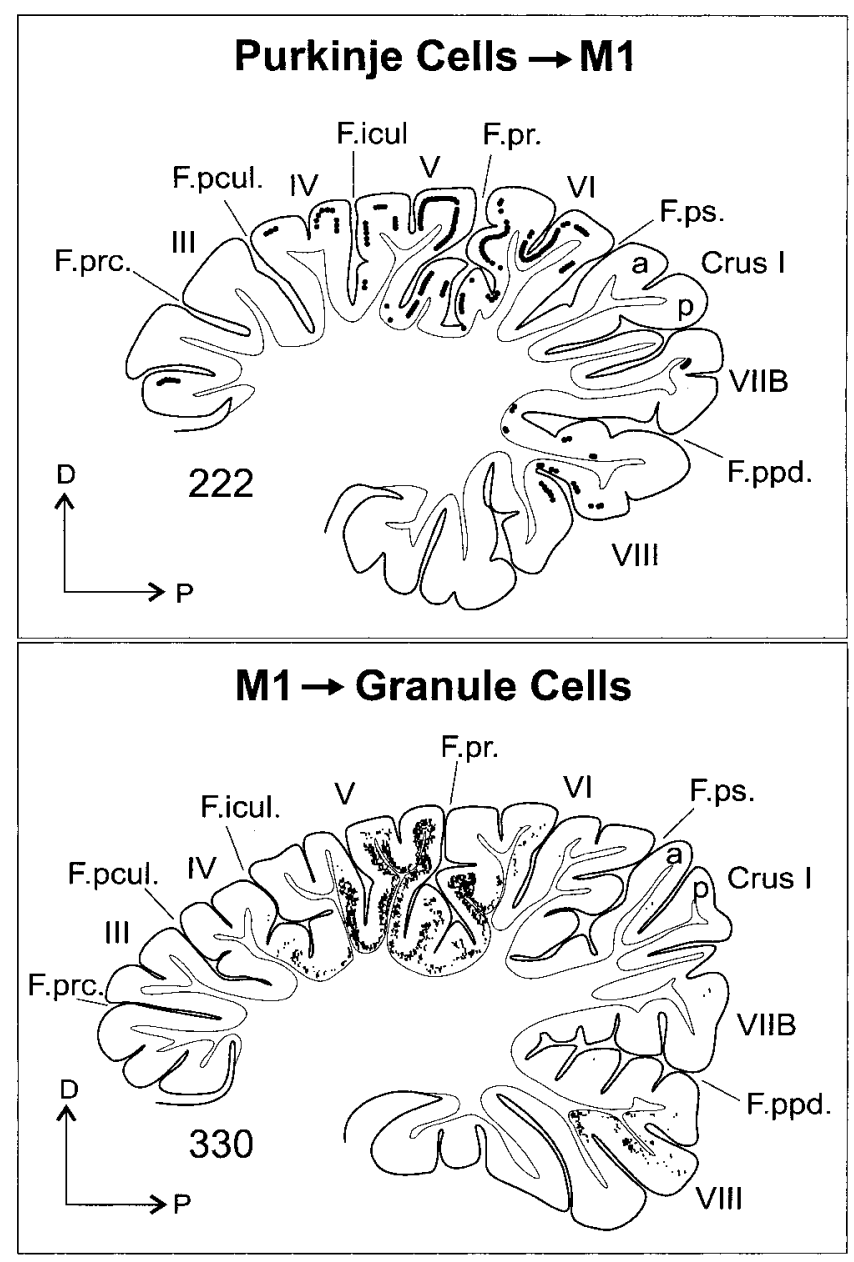

Figure 10. Location of cerebellar cortical neurons that are interconnected with M1. Top, A sagittal section displaying the distribution of Purkinje cells (large dots) that project to the arm area of M1 (section 222) (Fig. 9, left). The Purkinje cells were labeled after retrograde transneuronal transport of rabies from injections into the arm area of M1. Bottom, A sagittal section displaying the distribution of granule cells (small dots) that receive input from the arm area of M1 (section 330) (Fig. 9, right). These neurons were labeled after anterograde transneuronal transport of the H129 strain of HSV1 from injections into the arm area of M1. Scale bars, $3 \mathrm{~mm}$. Nomenclature and abbreviations are according to Larsell (1970).

\section{Area 46}

Four days after rabies injections into area 46, we found infected Purkinje cells in three separate regions of the cerebellar cortex contralateral to the injection site (Fig. 11, left; Fig. 12, top). Most of the labeled neurons ( $~ 85 \%$ of the sample) were located laterally in Crus II. They were primarily in superficial portions of this lobule rather than adjacent intracrural fissures. Labeled Purkinje cells formed small clusters similar to those found in more anterior portions of the cerebellum after virus injections into M1. The labeled Purkinje cells in Crus II began $11 \mathrm{~mm}$ from the midline and continued laterally for $6 \mathrm{~mm}$ to the edge of the hemisphere. A second smaller group of labeled Purkinje cells ( $\sim 12 \%$ of the sample) was located more posteriorly in vermal lobule X. Finally, a few labeled neurons ( $\sim 3 \%$ of the sample) were scattered in vermal portions of lobule VII.

The flattened and unfolded maps of the cerebellar cortex from individual experimental animals were sufficiently similar; thus, we were able to compare data from the different cortical injection sites. It was clear from this comparison that M1 and area 46 injections of rabies labeled Purkinje cells in very different regions of the cerebellar cortex. This observation indicates that the regions of the cerebellar cortex that influence M1 are entirely separate from those that influence area 46.

\section{Topographic arrangement of granule cells that receive input from $M 1$ and area 46}

Having identified the regions of the cerebellar cortex that project to M1 and area 46, a second goal of the present study was to determine the regions of cerebellar cortex that receive input from those cerebral cortical areas. This would enable us to define input-output relationships in the cerebellar cortex. In a previous study, we demonstrated that the H129 strain of HSV1 is transported transneuronally in the anterograde direction (Zemanick et al., 1991). For example, $4 \mathrm{~d}$ after intracortical injections of $\mathrm{H} 129$, the virus was transported transneuronally through first-, second-, and third-order neurons in the cortico-pontocerebellar pathway to label granule and Golgi cells in the cerebellar cortex (Fig. 13). In the present study, we used the H129 strain of HSV1 and a $4 \mathrm{~d}$ survival time to examine the distribution of granule cells that were labeled after virus injections into the arm area of M1 $(n=2)$ or area $46(n=2)$. In general, the number of granule cells labeled after cortical injections of $\mathrm{H} 129$ far exceeded the number of Purkinje cells that were labeled after similar injections of rabies. This was not unexpected, because granule cells outnumber Purkinje cells 1000:1 (Ito, 1984). Again, for ease of comparison, we present the results from one representative animal in each group whose cerebellar cortex was sectioned in the sagittal plane.

The optimal way to compare the distributions of labeled Purkinje and granule cells would be to inject both viruses at the same cortical sites. However, this comparison is not feasible because, in preliminary experiments, we found that the presence of HSV1 at the injection site interfered with rabies transport (our unpublished observations). Thus, it was necessary to examine material from separate animals injected with either rabies or HSV1 at comparable cortical sites.

\section{M1}

Four days after H129 injections in the arm area of M1, we found infected granule cells in two separate regions of the cerebellar cortex contralateral to the injection site (Fig. 9, right; Fig. 10, bottom). The majority of the labeled cells was located anteriorly in lobules V-VI. Dense clusters of labeled cells began $\sim 3 \mathrm{~mm}$ from the midline and continued for $7 \mathrm{~mm}$ laterally. The second group of labeled granule cells was located posteriorly in lobules HVIIB-HVIII. Clusters of labeled neurons in the posterior group were more dispersed and contained fewer neurons. Labeling in lobules HVIIB-HVIII began $5 \mathrm{~mm}$ from the midline and continued laterally for $8 \mathrm{~mm}$.

We compared the maps of granule cells labeled after H129 injections into M1 (Fig. 9, right, Z9) with the maps of Purkinje cells labeled after rabies injections into M1 (Fig. 9, left, K8). Both sets of maps contained spatially and numerically consistent patterns of labeling anteriorly in lobules V-VI and posteriorly in lobules HVIIB-HVIII. This included individual dense clusters of labeled neurons, which could be found at comparable locations in the two sets of maps on the surface of lobules V and VI and in the banks of the intraculminate and primary fissures. There were some differences in the maps of Purkinje and granule cells. Labeled Purkinje cells, after the M1 injections of rabies in K8, were found more anteriorly on the surface of lobule IV and in the preculminate fissure than labeled granule cells after the H129 injections in Z9. In contrast, more labeled granule cells in Z9 were found in the posterior superior fissure than labeled Purkinje cells 


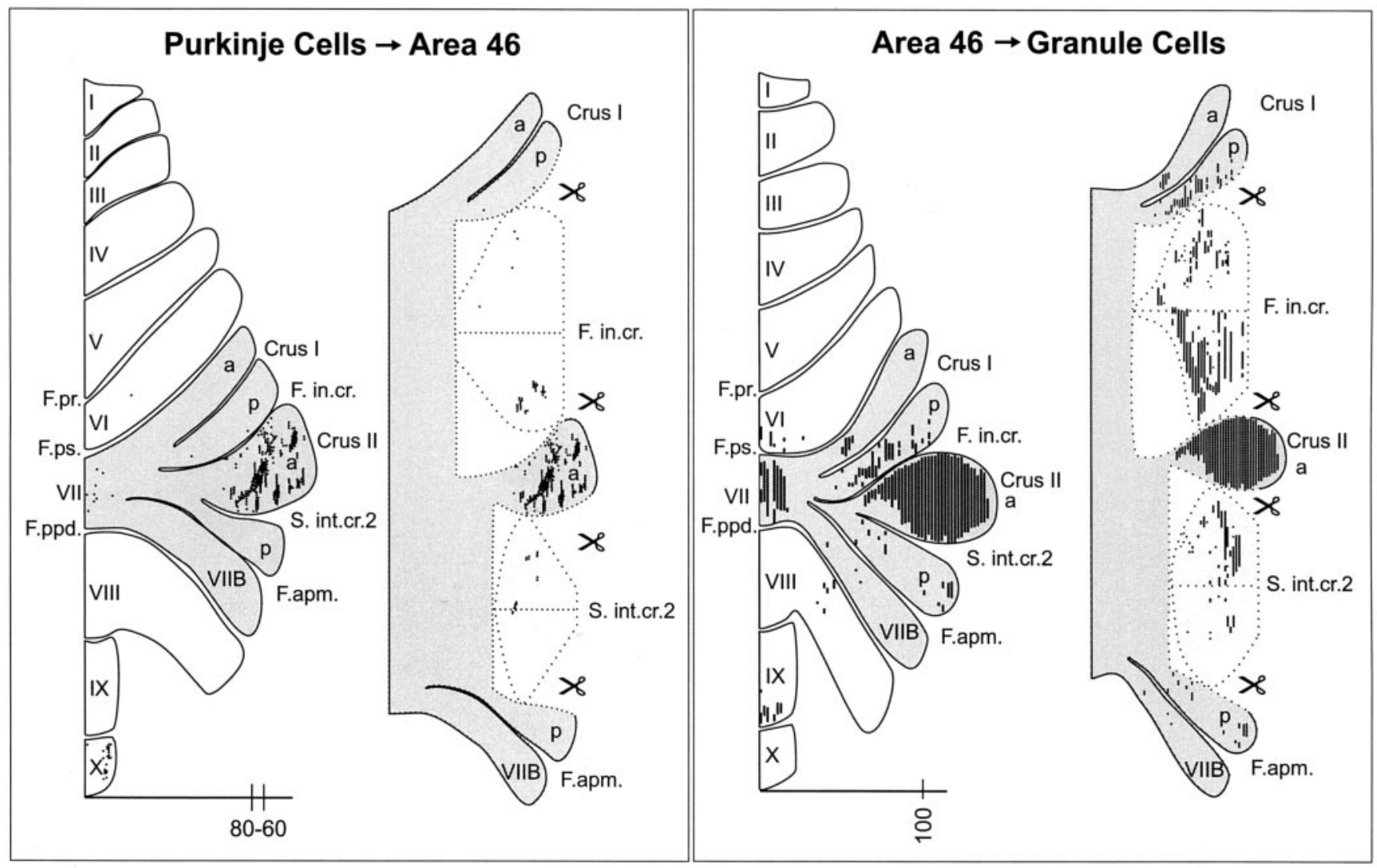

Figure 11. Input- output organization of the cerebellar loops with area 46. Left, The distribution of Purkinje cells (small dots) that project to area 46. Right, The distribution of granule cells (fine lines) that receive input from area 46. The shaded areas on the flattened surface maps (diagrams on the left in each panel) are unfolded on the right side of each panel to show the distribution of labeled neurons in the relevant cerebellar cortical fissures. (See Materials and Methods and Figure 9 legend for additional explanation). Scale bars, $15 \mathrm{~mm}$. Nomenclature and abbreviations are according to Larsell (1970). The numbers on the scale bars indicate the location of the sections displayed in Figure 12.

in K8. These differences in the maps of the two types of labeled neurons are likely to be attributable to differences in the virus injection sites. Although the sites overlapped considerably, they were not identical. The injections of rabies in K8 were made in the precentral gyrus and the anterior bank of the sulcus, whereas the injections of H129 in Z9 were confined to the precentral gyrus. In addition, the H129 injection site extended more rostrally in M1, and the rabies injection site extended more laterally (Fig. 8). Despite these differences, the substantial correspondence between the distributions of the two types of labeled neurons suggests that the regions of the cerebellar cortex that project to $\mathrm{M} 1$ are the same as those that receive input from M1.

\section{Area 46}

Four days after H129 injections in area 46, we found infected granule cells in three separate regions of the cerebellar cortex contralateral to the injection site (Fig. 11, right; Fig. 12, bottom). The majority of the labeled neurons was located in Crus II. Dense labeling in Crus II began $8 \mathrm{~mm}$ from the midline and continued laterally for $9 \mathrm{~mm}$ to the edge of the hemisphere. Two smaller groups of labeled granule cells were located posteriorly in vermal lobules VII and IX.

We compared the maps of granule cells labeled after H129 injections into area 46 (Fig. 11, right, K14) with the maps of Purkinje cells labeled after rabies injections into area 46 (Fig. 11, left, K11). Dense labeling was present on the surface of Crus II on both sets of maps. However, labeled granule cells were generally more widely distributed in the cerebellar cortex than labeled Pur- kinje cells. For instance, there were more labeled granule cells on the surface of Crus II, within the intracrural fissures, and in vermal lobule VII compared with labeled Purkinje cells. Also, labeled granule cells in the most posterior region of the vermis were shifted anteriorly compared with Purkinje cells. These differences in the distributions of labeled granule and Purkinje cells most likely reflect that the H129 injection site in K14 was larger than the rabies injection site in K11 (Fig. 8). Despite these differences, the overlap of granule cell and Purkinje cell labeling in Crus II suggests that the regions of the cerebellar cortex that project to area 46 are the same as the regions that receive input from area 46.

\section{Discussion}

\section{Methodological considerations}

Retrograde transneuronal transport of neurotropic viruses has been used previously to examine the distribution of neurons that are disynaptically linked to an injection site. Our adaptation of rabies virus for transneuronal tracing in primates enabled us to reveal connections in chains of three or more synaptically linked neurons (Kelly and Strick, 2003). The additional technical advantages of using rabies virus as a tracer, as well as biosafety concerns, have been discussed previously (Ugolini, 1995; Kelly and Strick, 2000). However, one technical issue that has not been described in detail is that rabies displays limited spread from injection sites in the CNS. Even after relatively large deposits of virus and survival times longer than $2 \mathrm{~d}$, the effective site of virus uptake appears to be limited to a $200-500 \mu \mathrm{m}$ radius from the site of 


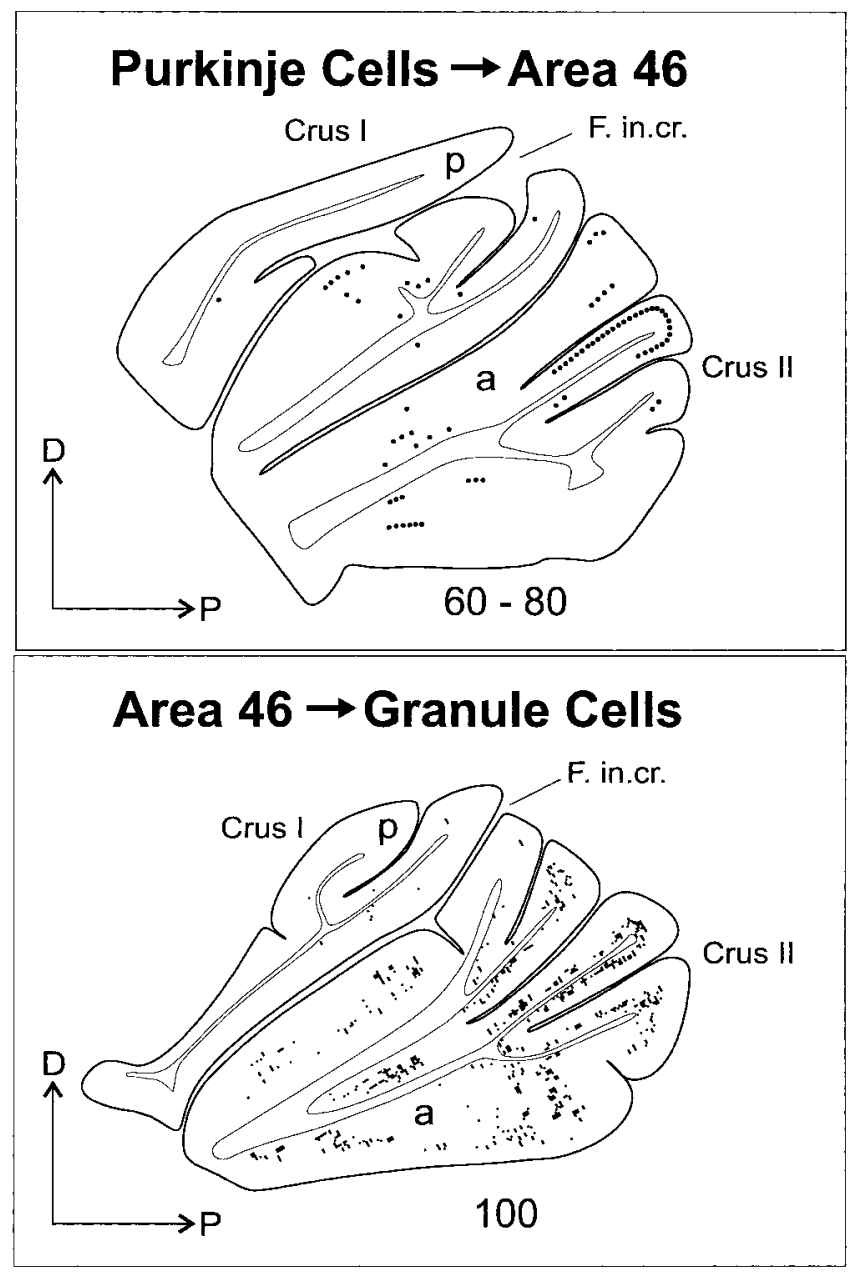

Figure 12. Location of cerebellar cortical neurons that are interconnected with area 46. Top, A composite of the sagittal sections displaying the distribution of Purkinje cells (large dots) that project to area 46 (sections $60-80$ ) (Fig. 11, left). Every fourth section was used to make this composite. Bottom, A sagittal section displaying the distribution of granule cells (small dots) that receive input from area 46 (section 100) (Fig. 11, right). Nomenclature and abbreviations are according to Larsell (1970).

injection needle penetration. The limited diffusion of rabies along with the absence of overt destruction of infected neurons make rabies virus an especially useful tool for examining the structure of neural systems that have a high degree of topographic specificity.

\section{The architecture of cerebrocerebellar circuits}

The use of rabies virus and the $\mathrm{H} 129$ strain of HSV1 as transneuronal tracers revealed four new observations about the architecture of cerebrocerebellar circuitry. First, Purkinje cells that influence specific areas of the cerebral cortex via cerebello-thalamocortical connections are in localized regions of the cerebellar cortex. Second, the regions of the cerebellar cortex that influence M1 are entirely separate from those that influence area 46. Third, the regions of the cerebellar cortex that receive input from M1 via corticopontocerebellar connections are the same as those that project to M1. Similarly, the regions of the cerebellar cortex that receive input from area 46 are the same as those that project to area 46 .

At this point, we cannot say whether the specific Purkinje cells that project to an area of the cerebral cortex are a target of efferents from the same area of the cortex. We found that multiple
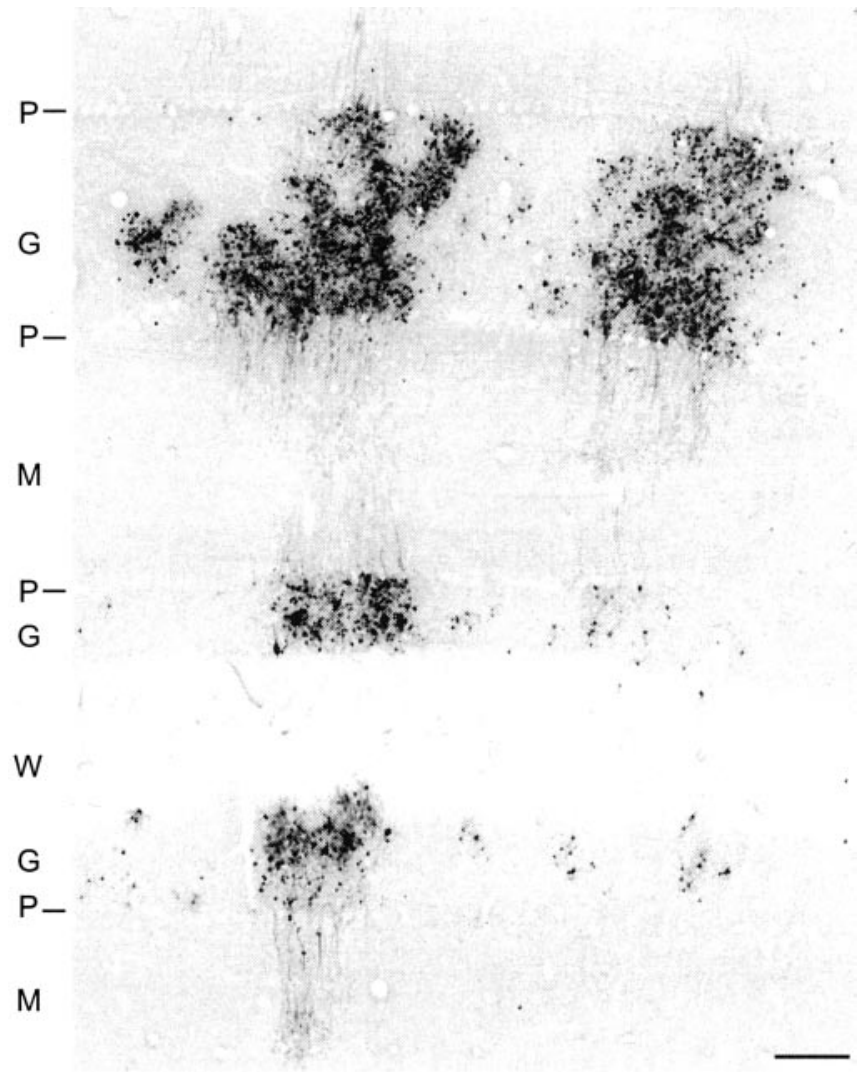

Figure 13. Transverse section through the cerebellar cortex showing dense clusters of granule cells labeled by anterograde transneuronal transport of $\mathrm{H} 129$ from an injection site into M1. Granule cell axons can be seen ascending to the molecular layer, but Purkinje cells remain free of antigen. Scale bar, $200 \mu \mathrm{m}$. P, Purkinje cell layer; G, granule cell layer; M, molecular layer; W, white matter.

patches of Purkinje cells project to a given cortical area, and multiple patches of granule cells receive input from that cortical area. The Purkinje cell patches may be in or out of register with the granule cell patches. However, at the macro level, our results indicate that closed-loop circuits are a fundamental unit of architecture for cerebellar interconnections with the cerebral cortex (Fig. 14).

\section{The cerebellar cortical map}

In previous studies, we used retrograde transneuronal transport of HSV1 to examine the organization of dentate projections to areas of motor, premotor, oculomotor, prefrontal, and posterior parietal cortex (Hoover and Strick, 1993, 1999; Lynch et al., 1994; Middleton and Strick, 1994, 2001; Clower et al., 2001). The results of these studies showed that each cortical area is the target of an anatomically distinct output channel in the dentate. When these output channels are displayed on a flattened map of the dentate, it is clear that the nucleus contains distinct motor and nonmotor domains (Dum and Strick, 2003). The present results demonstrate that the segregation of output channels that project to M1 and area 46 is maintained at the level of the cerebellar cortex. These observations imply that the cerebellar cortex is organized into separate motor and nonmotor domains similar to those found in the dentate nucleus.

Major progress in defining principles of organization for the cerebral cortex has come from detailed investigations into the number, location, and connectivity of its distinct areas (Felleman 


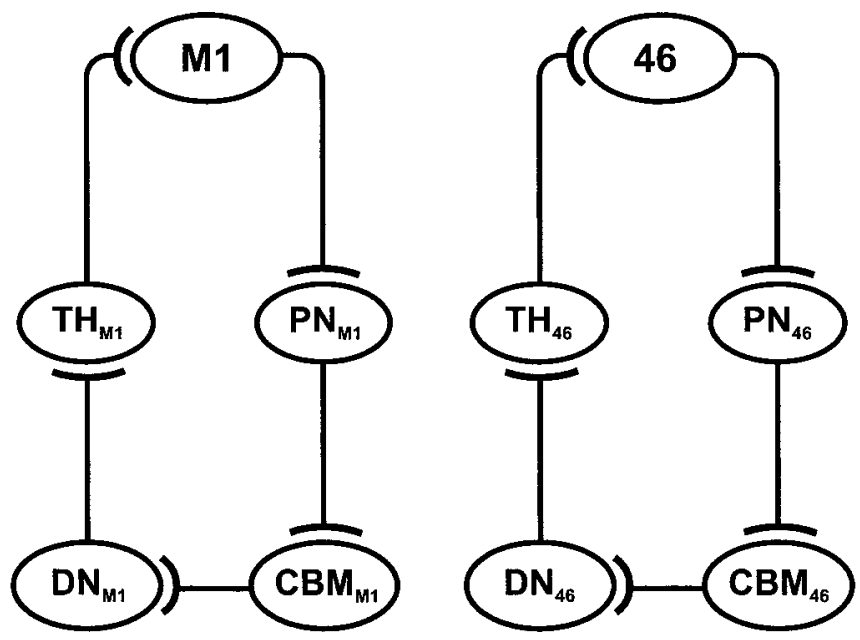

Figure 14. Summary diagrams of the closed-loop circuits that link the cerebellum with M1 and area 46. Note that the cortical area, which is the major source of input to a circuit, is the major target of output from the circuit. See Discussion for complete details. CBM, Cerebellar cortex; DN, dentate nucleus; PN, pontine nuclei; $\mathrm{TH}$, subdivisions of the thalamus.

and Van Essen, 1991). Comparable investigations into the number, location, and connectivity of the distinct subdivisions of the cerebellar cortex will be critical to additional insights into its functional organization. Experiments that use transneuronal transport of neurotropic viruses provide a means for defining how the cerebral cortex maps on the cerebellar cortex. The present results suggest that the map of function in the cerebellar cortex is likely to be as rich and complex as that in the cerebral cortex. In this context, one might question the use of descriptors like cerebellar patient, which tend to de-emphasize the importance of the functional topography of the cerebellar cortex. For example, lesions that damage regions of cerebellar cortex, which are interconnected with area 46, are unlikely to cause motor deficits, just as lesions that damage cerebellar cortical regions, which are interconnected with $\mathrm{M} 1$, are unlikely to result in cognitive deficits. Thus, precisely defining the location of a lesion, site of activation, or recording site is as important for studies of the cerebellum as it is for studies of the cerebral cortex.

\section{Functional considerations}

Our observations challenge long-held concepts about the architecture of cerebellar loops with the cerebral cortex. As noted in the Introduction, the classical view is that the cerebellum provides a substrate by which widespread areas of the cerebral cortex can influence the generation and control of movement at the level of M1 (Evarts and Thach, 1969; Kemp and Powell, 1971; Allen and Tsukahara, 1974). For example, Glickstein (2000) proposed that cerebrocerebellar circuits are the major route by which signals from visual areas of the cerebral cortex provide M1 with information to guide reaching movements. In a similar manner, cerebrocerebellar circuits were thought to enable the cognitive processing in prefrontal cortex to have an impact on the generation of motor commands in M1. These concepts imply that considerable convergence takes place in cerebrocerebellar circuits. The convergence could happen at two sites: widespread regions of the cerebral cortex could innervate localized sets of Purkinje cells, or Purkinje cells in widespread regions of the cerebellar cortex could converge on localized sets of neurons in the deep cerebellar nuclei. Virus tracing enabled us to examine this issue in relation to two cortical areas, M1 and area 46. We found that M1 receives input from Purkinje cells located primarily in lobules HIV-HVI. Furthermore, we found no evidence that inputs from area 46 gain access to these Purkinje cells. Instead, efferents from area 46 project primarily to an entirely separate region of the cerebellar cortex, Crus II. Thus, our observations fail to provide support for the concept that convergence represents a major feature of cerebrocerebellar processing.

We do not mean to imply that convergence is entirely absent in cerebrocerebellar circuitry. Virus injections into M1 labeled neurons (Purkinje cells or granule cells) not only in lobules HIVHVI but also in lobules HVIIB-HVIII. The locations of these two sets of labeled neurons correspond closely to the two arm representations present in the classic physiological maps of the cerebellar cortex (Adrian, 1943; Snider and Eldred, 1952; Sasaki et al., 1977). Likewise, virus injections into area 46 labeled neurons not only in Crus II but also in vermal lobules VII and X. These observations indicate that $\mathrm{M} 1$ and area 46 each receive input from more than one site in the cerebellar cortex. Similarly, M1 and area 46 each project to more than one site in the cerebellar cortex. Thus, convergence and divergence do exist in the cerebrocerebellar system. However, these interactions operate on a smaller functional scale than previously conceived.

Our observations lead us to propose that there are separate cerebrocerebellar circuits for cognitive as well as motor operations (Fig. 14). A complete review of the literature and evidence for the involvement of the cerebellar cortex in movement and cognition is clearly beyond the scope of this study (for review, see Schmahmann, 1997). However, we would like to highlight data from one functional imaging study that supports our suggestion. Desmond et al. (1997) reported differential patterns of cerebellar activation during motor and cognitive tasks. Increased activation was present in lobules HIV-HVI and in lobule HVIII when their human subjects performed a finger-taping task. The location of these sites appears to correspond to regions of the monkey cerebellar cortex that are interconnected with M1. In contrast, increased activation was present in lobule HVIIa and in vermal lobules VI and VIIa when the same subjects performed a working memory task. The location of these sites appears to correspond to regions of the monkey cerebellar cortex that are interconnected with area 46 . Thus, the areas we identified in the monkey cerebellar cortex appear to have their counterparts in the human cerebellar cortex.

Imaging studies also provide evidence that the closed-loop architecture we identified is functionally relevant. Raichle et al. (1994) observed increased activation in a region of the left lateral prefrontal cortex and in a region of the right cerebellar hemisphere when subjects were learning to perform the verb generation task. This task required subjects to generate an appropriate verb in response to the presentation of a noun. The activity at both the prefrontal and cerebellar sites declined as subjects became proficient at generating verbs for a particular list of nouns. When the subjects were presented with a new list of nouns, the prefrontal and cerebellar activations again increased. Thus, the sites of activation in prefrontal cortex and the cerebellum appeared to be linked in a manner that is appropriate for closed-loop architecture. Additional support for a prefrontal cerebellar linkage comes from functional imaging studies in schizophrenics, in which sites in the prefrontal cortex and cerebellar hemisphere of patients display reduced activation during a recall task relative to control subjects (Andreasen et al., 1996). 
In summary, our results demonstrate that M1 and area 46 are interconnected with separate regions of the cerebellar cortex. This suggests that the cerebellar cortex is not a major site for interactions between the cerebral systems concerned with movement and cognition. A common closed-loop architecture describes the organization of cerebrocerebellar interconnections with M1 and area 46. A challenge for future studies is to determine the computations that are supported by this architecture. Whatever these computations are, they will be relevant to cognitive processing as well as generation and control of movement.

\section{References}

Adrian ED (1943) Afferent areas in the cerebellum connected with the limbs. Brain 66:289-315.

Allen GI, Tsukahara N (1974) Cerebrocerebellar communication systems. Physiol Rev 54:957-1006.

Andreasen NC, O'Leary DS, Cizadlo T, Arndt S, Rezal K, Boles Ponto LL, Watkins GL, Hichwa RD (1996) Schizophrenia and cognitive dysmetria: a positron-emission tomography study of dysfunctional prefrontalthalamic-cerebellar circuitry. Proc Natl Acad Sci USA 93:9985-9990.

Barbas H, Pandya DN (1989) Architecture and intrinsic connections of the prefrontal cortex in the Rhesus monkey. J Comp Neurol 286:353-375.

Brodal P (1978) The corticopontine projection in the rhesus monkey. Origin and principles of organization. Brain 101:251-283.

Chan-Palay V (1977) Cerebellar dentate nucleus. Organization, cytology and transmitters. Berlin: Springer.

Charlton KM, Casey GA (1979) Experimental rabies in skunks. Immunofluorescence light and electron microscopic studies. Lab Invest 41:36-44.

Clower DM, West RA, Lynch JC, Strick PL (2001) The inferior parietal lobule is the target of output from the superior colliculus, hippocampus, and cerebellum. J Neurosci 21:6283-6291.

Desmond JE, Gabrieli JDE, Wagner AD, Ginier BL, Glover GH (1997) Lobular patterns of cerebellar activation in verbal working-memory and finger-tapping tasks as revealed by functional MRI. J Neurosci 17:9675-9685.

Dum RP, Strick PL (1991) Premotor areas: nodal points for parallel efferent systems involved in the central control of movement. In: Motor control: concepts and issues (Humphrey DR, Freund H-J, eds), pp 383-397. London: Wiley.

Dum RP, Strick PL (2003) An unfolded map of the cerebellar dentate nucleus and its projections to the cerebral cortex. J Neurophysiol 89:634-639.

Eager RP (1966) Patterns and mode of termination of cerebellar corticonuclear pathways in the monkey (Macaca mulatta). J Comp Neurol 126:551-566.

Evarts EV, Thach WT (1969) Motor mechanisms of the CNS: cerebrocerebellar interrelations. Annu Rev Physiol 31:451-498.

Felleman DJ, Van Essen DC (1991) Distributed hierarchical processing in the primate cerebral cortex. Cereb Cortex 1:1-47.

Gillet JP, Derer P, Tsiang H (1986) Axonal transport of rabies virus in the central nervous system of the rat. J Neuropathol Exp Neurol 45:619-634.

Glickstein M (2000) How are visual areas of the brain connected to motor areas for the sensory guidance of movement. Trends Neurosci 23:613-617.

Glickstein M, May JG, Mercier BE (1985) Corticopontine projection in the macaque: the distribution of labelled cortical cells after large injections of horseradish perioxidase in the pontine nuclei. J Comp Neurol 235:343-359.

Haines DE, Rubertone JA (1979) Cerebellar corticonuclear fibers of the dorsal culminate lobule (anterior lobe-lobule $\mathrm{V}$ ) in a prosimian primate, Galago senegalensi. J Comp Neurol 186:321-342.

Holsapple JW, Preston JB, Strick PL (1991) The origin of thalamic inputs to the "hand" representation in the primary motor cortex. J Neurosci 11:2644-2654.

Hoover JE, Strick PL (1993) Multiple output channels in the basal ganglia. Science 259:819-821.

Hoover JE, Strick PL (1999) The organization of cerebellar and basal ganglia outputs to primary motor cortex as revealed by retrograde transneuronal transport of herpes simplex virus type 1. J Neurosci 19:1446-1463.
Ito M (1984) The cerebellum and neural control. New York: Raven.

Iwasaki Y, Clark HF (1975) Cell to cell transmission of virus in the central nervous system. II. Experimental rabies in mouse. Lab Invest 33:391-399.

Jones EG (1985) The thalamus. New York: Plenum.

Kelly RM, Strick PL (1997) Retrograde transneuronal transport of rabies virus through the cerebelo-thalamocortical circuits of primates. Soc Neurosci Abstr 23:1828.

Kelly RM, Strick PL (1998) Cerebro-cerebellar 'loops' are closed. Soc Neurosci Abstr 24:1407.

Kelly RM, Strick PL (2000) Rabies as a transneuronal tracer of circuits in the central nervous system. J Neurosci Methods 103:63-71.

Kelly RM, Strick PL (2003) Macro-architecture of basal ganglia loops with the cerebral cortex: use of rabies virus to reveal multisynaptic circuits. Prog Brain Res, in press.

Kemp JM, Powell TPS (1971) The connexions of the striatum and globus pallidus: synthesis and speculation. Philos Trans R Soc Lond B Biol Sci 262:441-457.

Kunzle H (1975) Bilateral projections from precentral motor cortex to the putamen and other parts of the basal ganglia. An autoradiographic study in Macaca fascicularis. Brain Res 88:195-209.

Kuypers HGJM (1981) Anatomy of the descending pathways. In: Handbook of physiology. Section I: the nervous system, Vol II, Motor control, Pt I (Brooks VB, ed), pp 567-666. Bethesda: American Physiological Society.

Larsell O (1970) The comparative anatomy and histology of the cerebellum from monotremes through apes. Minneapolis: The University of Minnesota.

Lynch JC, Hoover JE, Strick PL (1994) Input to the primate frontal eyefield from the substantia nigra, superior colliculus, and dentate nucleus demonstrated by transneuronal transport. Exp Brain Res 100:181-186.

Matelli M, Luppino G, Fogassi L, Rizzolatti G (1989) Thalamic input to inferior area 6 and area 4 in the macaque monkey. J Comp Neurol 280:468-488.

Middleton FA, Strick PL (1994) Anatomical evidence for cerebellar and basal ganglia involvement in higher cognitive function. Science 266:458-461.

Middleton FA, Strick PL (1998) Cerebellar output: motor and cognitive channels. Trends Cogn Sci 2:348-354.

Middleton FA, Strick PL (2001) Cerebellar projections to the prefrontal cortex of the primate. J Neurosci 21:700-712.

Nakano K, Takimoto T, Kayahara T, Takeuchi Y, Kobayashi Y (1980) Distribution of cerebellothalamic neurons projecting to the ventral nuclei of the thalamus: an HRP study in the cat. J Comp Neurol 194:427-439.

Olsewski J (1952) The thalamus of the Macaca mulatta. New York: Karger.

Parent A, Hazrati L (1995) Functional anatomy of the basal ganglia. I. The cortico-basal ganglia-thalamo-cortical loop. Brain Res Brain Res Rev 20:91-127.

Parent A, Smith Y (1987) Organization of efferent projections of the subthalamic nucleus in the squirrel monkey as revealed by retrograde labeling methods. Brain Res 436:296-310.

Percheron G, Francois C, Talbi B, Yelnik J, Fenelon G (1996) The primate motor thalamus. Brain Res Brain Res Rev 22:93-181.

Raichle ME, Fiez JA, Videen TO, MacLeod AK, Pardo JV, Fox PT, Petersen SE (1994) Practice-related changes in human brain functional anatomy during nonmotor learning. Cereb Cortex 4:8-26.

Rosene DL, Mesulam MM (1978) Fixation variables in horseradish peroxidase neurohistochemistry. I. The effects of fixation time and perfusion procedures upon enzyme activity. J Histochem Cytochem 26:28 -39.

Sasaki K, Oka H, Kawaguchi S, Jinnai K, Yasuda T (1977) Mossy fibre and climbing fibre responses produced in the cerebellar cortex by stimulation of the cerebral cortex in monkeys. Exp Brain Res 29:419-428.

Schmahmann JD (1997) The cerebellum and cognition. Int Rev Neurobiol $41: 1-660$.

Schmahmann JD, Pandya DN (1997) Anatomic organization of the basilar pontine projections from prefrontal cortices in rhesus monkey. J Neurosci 17:438-458.

Snider RS, Eldred E (1952) Cerebro-cerebellar relationships in the monkey. J Neurophysiol 15:27-40.

Strick PL, Card JP (1992) Transneuronal mapping of neural circuits with alpha herpesviruses. In: Experimental neuroanatomy: a practical approach (Bolam JP, ed), pp 81-101. Oxford: Oxford UP. 
Strick PL, Hoover JE, Mushiake H (1993) Evidence for 'output channels' in the gasal ganglia and cerebellum. In: Role of the cerebellum and basal ganglia in voluntary movement (Mano N, Hamada I, DeLong MR, eds), pp 171-180. Amsterdam: Elsevier.

Tolbert DL, Bantli H (1979) An HRP and autoradiographic study of cerebellar corticonuclear-nucleocortical reciprocity in the monkey. Exp Brain Res 36:563-571.

Tolbert D, Bantli H, Bloedel J (1978) Multiple branching of cerebellar efferent projections in cats. Exp Brain Res 31:305-316.

Ugolini G (1995) Specificity of rabies virus as a transneuronal tracer of motor networks: transfer from hypoglossal motoneurons to connected second-order and higher order central nervous system cell groups. J Comp Neurol 356:457-480.

Walker A (1940) A cytoarchitectural study of the prefrontal area of the macaque monkey. J Comp Neurol 73:59-86.

Woolsey CN, Settlage P, Meyer D, Sencer W, Pinto-Hamuy T, Travis A (1952) Patterns of localization in precentral and "supplementary" motor areas and their relation to the concept of a premotor area. J Nerv Ment Dis 30:238-264.

Zemanick MC, Strick PL, Dix RD (1991) Direction of transneuronal transport of herpes simplex virus 1 in the primate motor system is straindependent. Proc Natl Acad Sci USA 88:8048-8051. 